\title{
Redescription of the pupa of Mallochohelea termophila (Diptera: Ceratopogonidae)
}

\section{Redescripción de la pupa de Mallochohelea termophila (Diptera: Ceratopogonidae)}

\author{
María M. Ronderos ${ }^{\bowtie}$ and Gustavo R. Spinelli \\ División Entomología, Museo de La Plata, Paseo del Bosque, 1900 La Plata, Argentina, CCT La Plata-CEPAVE, ILPLA. \\ هronderos@fcnym.unlp.edu.ar
}

\begin{abstract}
The pupal exuvia of Mallochohelea termophila (Spinelli) is redescribed, photographed and illustrated mainly based on the type-series. Pupae of the type-series were collected with forceps from a thermal stream and were attached to rocks about $200 \mathrm{~m}$ from the spring head. Pupae from Uruguay were collected with a dipper in lotic and lentic environments. They were reared to adults in the laboratory. This is the first detailed pupal description of a species of Mallochohelea, and the first record of this species from Uruguay. Similarities and differences with the pupae of Neobezzia are provided.
\end{abstract}

Key words: immature, Mallochohelea thermophila, redescription, Ceratopogonidae.

Resumen. Se describe, fotografía e ilustra la exuvia pupal de Mallochohelea termophila (Spinelli), en especial sobre la base de la serie-tipo. Las pupas de la serie-tipo fueron recolectadas mediante pinzas en un arroyo termal, adheridas a rocas, aproximadamente a $200 \mathrm{~m}$ del manatial y las pupas de Uruguay mediante el uso de un cucharón tanto en ambientes lóticos como lénticos. Ellas fueron criadas hasta adultos en el laboratorio. Ésta es la primera descripción detallada de una pupa de una especie de Mallochohelea y el primer registro de la especie para Uruguay. Se destacan semejanzas y diferencias con las pupas de Neobezzia.

Palabras clave: inmaduro, Mallochohelea thermophila, redescripción, Ceratopogonidae.

\section{Introduction}

The worldwide genus Mallochohelea Wirth belongs to the tribe Sphaeromiini, and it is represented in the Neotropical region by 6 known species (Borkent and Spinelli, 2007). Five of these are known only from Brazil, Guyana, northern Argentina and Uruguay. Mallochohelea pullata (Wirth) ranges from the USA (California, Arizona and Texas) south to Brazil (Amapa). The immature stages of the genus are poorly known, being described the pupae of 12 named species and 2 unnamed ones (Borkent, pers. comm.). The descriptions of the known pupae, as well as the ones in other Sphaeromiini genera, are incomplete and superficial. With regard to the Neotropical species of Mallochohelea, only the pupa of M. termophila (Spinelli), a species known from the Amazon area of Rondonia in Brazil and northern Argentina, has been previously described (Spinelli, 1984).

The purpose of this paper is to take the first steps towards the improvement of the scarce current knowledge on the morphology of the Sphaeromiini pupae, by fully describing the pupa of $M$. termophila from the type-series,

Recibido: 12 diciembre 2011; aceptado: 15 febrero 2012 as well as from specimens subsequently collected in Uruguay.

\section{Materials and methods}

Pupae of the type-series of Mallochohelea termophila were collected with forceps from a thermal stream, attached to rocks by their glandular windows on abdominal segments 6 and 7. They were located about $200 \mathrm{~m}$ from the spring head where the water temperature was $28^{\circ} \mathrm{C}$ and the $\mathrm{pH}$ 7.2. The pupae from Uruguay were collected with a dipper in both, lentic and lotic environments. In all cases, the pupae were transported to the laboratory individually in vials with a drop of water from their original habitats. Observations were made daily until adult emergence. Adults were allowed to harden for 24 hours before being preserved to ensure their pigmentation was complete. Pupal exuviae were examined using a binocular compound microscope (BCM) after being slide-mounted dorsoventrally in Canada balsam following the technique described by Wirth and Marston (1968). Ink illustrations were made with a camera lucida. Photomicrographs were taken with a Micrometric digital camera through a NIKON (10X or 40X). Terminology of the pupa follows Borkent and Craig (2001). 


\section{Description}

Mallochohelea termophila (Spinelli) (Figs. 1-21) Neobezzia termophila Spinelli, 1984: 197 (female, male, pupa; Argentina).

Mallochohelea termophila: Spinelli and Wirth, 1993: 58 (new combination; in list of Argentinean species); Borkent and Wirth, 1997: 120 (in world catalog); Borkent and Spinelli, 2000: 58 (in catalog of species south of USA); Borkent and Spinelli, 2007: 91 (in Neotropical catalog); Borkent, 2012: 147 (online catalog).

Male pupa. Exuviae brown (Fig. 1). Operculum (Figs. $11,17)$ with disc wider than long, OL $0.12-0.15(0.13$, $\mathrm{n}=2) \mathrm{mm}$, OW 0.17-0.20 (0.18, $\mathrm{n}=2) \mathrm{mm}$, OW/OL 0.70-0.75 $(0.72, n=2)$; anterior margin pointed, surface covered with small, rounded tubercles; each side of mesal portion with pair of raised areas, ventral one blunt, with anteromarginal seta long, thin, dorsal one with large pore; 2 stout ventromedian setae (vm, Figs. 9, 19), 1 medium-sized, other short; 2 elongate ventrolateral setae (vl) thinner than vm, lateral pore present (Figs. 9, 19). Respiratory organ (Figs. 1-2, 7, 16) relatively short, broad, 3 times longer than broad, RO length $0.10-0.12$ $(0.11, \mathrm{n}=3) \mathrm{mm}, \mathrm{RO}$ width $0.030-0.036(0.033, \mathrm{n}=3)$ $\mathrm{mm}$, surface smooth, apex with 8-10 spiracles in 2 rows; pedicel (P) short, stout (Figs. 2, 7, 10, 12), pedicel length $0.010-0.012(0.011, \mathrm{n}=3) \mathrm{mm}, \mathrm{P} / \mathrm{RO} 0.1(\mathrm{n}=3)$. Cephalothorax (Fig. 2) length $1.22 \mathrm{~mm}$, width $0.80 \mathrm{~mm}$; medial longitudinal crest small, crenulate, extending between bases of respiratory organs; cephalothoracic setae as follows: 2 anterodorsal sensilla (ad, Figs. 8, 16), 1 peg, other pore; one medium-sized, stout dorsolateral seta (dl, Figs. 8, 16); 2 dorsomedian setae (dm, Figs. $8,16), 1$ long, thin, other spur, pore present; 6 dorsal setae (Figs. 10,18) on rounded tubercles: i-iii pegs, iv medium-sized, thin, v-vi pores. Abdominal segments covered with small pointed spicules, each segment with small pigmented anterolateral spiracular scar. Abdominal tergites $1-7$ with dorsal anterosubmarginal setae i (dasm i) on rounded tubercle, dorsal posteromedian i (d.p.m. i) on short, sclerotized tubercle, each of these tubercles arising directly from surrounding cuticle, pore below dasm $i$ and ii. First abdominal segment (Figs. 1, 20) with sensilla as follows: 3 anterior setae, i short stout seta, ii mediumsized, thin, seta, iii pore on mesal portion; 4 posterior setae: i minute, ii pore, iii peg, iv, long, thin setae; 4 lateral sensilla: 1 long thin seta, other short seta, other peg, remaining pore. Fourth abdominal segment (Figs. 1, $3,21)$ with 2 dorsal anterosubmarginal setae, 1 pore: i, medium-sized, thin seta, ii long, thin seta, iii pore; 4 dorsal posteromarginal setae (dpm), 1 pore: i, iv peg, ii absent, iii pore, $v$ long, thin seta; 1 lateral anterosubmarginal seta (lasm), long, thin on strong triangular tubercle; 3 lateral posteromarginal setae $(\mathrm{lpm})$ : $i$, short, thin seta on stout triangular tubercle with minute spines, ii long, thin seta on small base, iii minute seta on small base; 3 ventral posteromarginal setae, i medium-sized, thin, ii long, thin, iii thin, shorter than i, i-ii on small tubercles; iii on well developed, stout, bifid tubercle. Abdominal sternites 6, 7, each with large disc like glandular areas. Anal segment (Figs. 1, 5-6) twice longer than greatest width, ASL 0.37$0.39(0.38, \mathrm{n}=3) \mathrm{mm}$, ASW 0.16-0.21 (0.19, $\mathrm{n}=3) \mathrm{mm}$; lateral margins convex, ventral surface with abundant small spicules, posteriorly directed tubercles not extending to base of apicolateral processes. Apicolateral process (Figs. 1, 5) stout, curved, divergent, with pointed spicules, base broad, 1 ventral pore on base, tip pointed, length $0.22(\mathrm{n}=2) \mathrm{mm}$.

Female pupa. Similar to male with sexual differences: Total length $4.27 \mathrm{~mm}$. Operculum (Figs. 12-13) with triangular disc, anterior end very pointed; OL $0.12 \mathrm{~mm}(\mathrm{n}=$ 5); OW 0.20-0.21 (0.204, $\mathrm{n}=5) \mathrm{mm}$; OW/OL 1.70-1.75 $(1.72, \mathrm{n}=5)$. Respiratory organ (Fig. 12) length $0.10-0.13$ $(0.12, \mathrm{n}=5) \mathrm{mm}$; width $0.036-0.043(0.038, \mathrm{n}=5) \mathrm{mm}$; pedicel (Fig. 12) length $0.010-0.12(0.011, n=5) \mathrm{mm} ; \mathrm{P} /$ RO 0.080-0.100 (0.096, n= 5). Cephalothorax (Fig. 12) length 1.41-1.58 $(1.48, \mathrm{n}=5) \mathrm{mm}$, width $0.90(\mathrm{n}=4) \mathrm{mm}$; ventral setae slightly shorter than male (Fig. 14). Anal segment (Fig. 15) sharply pointed, with pointed spinules, ASL 0.38-0.43 (0.39, $\mathrm{n}=5) \mathrm{mm}$, ASW 0.20-0.26 (0.24, $\mathrm{n}=$ 5) $\mathrm{mm}$, APL 0.22-0.24 $(0.236, \mathrm{n}=5) \mathrm{mm}$.

\section{Taxonomic summary}

Distribution. Brazil (Rondonia), Uruguay, and northern Argentina.

Specimens examined. Argentina, Jujuy, Caimancito, 12-VIII-1980, E. Domizi-G. Spinelli, 1 male, 5 female paratypes; Uruguay, Artigas, arroyo Lenguazo and ruta nacional 3, 8-XI-1985, E. Balseiro-G. Spinelli, 1 male; Cañada de Cousillas, 20-IV-1985, G. Spinelli, 1 male. All specimens were collected as pupae and reared in the laboratory, and are deposited in the collection of the Museo de La Plata, Argentina (MLPA).

\section{Discussion}

The pupa of Mallochohelea termophila is similar to the known pupae of the genus Neobezzia Wirth and Ratanaworabhan. Both genera have the abdominal tergites 1-7 with d.a.s.m. i and d.p.m. i on short sclerotized tubercles, and the fourth abdominal sternite with v.p.m. iii on a bifid tubercle. However, the pupae of Neobezzia have a triangular operculum, 13 spiracles 

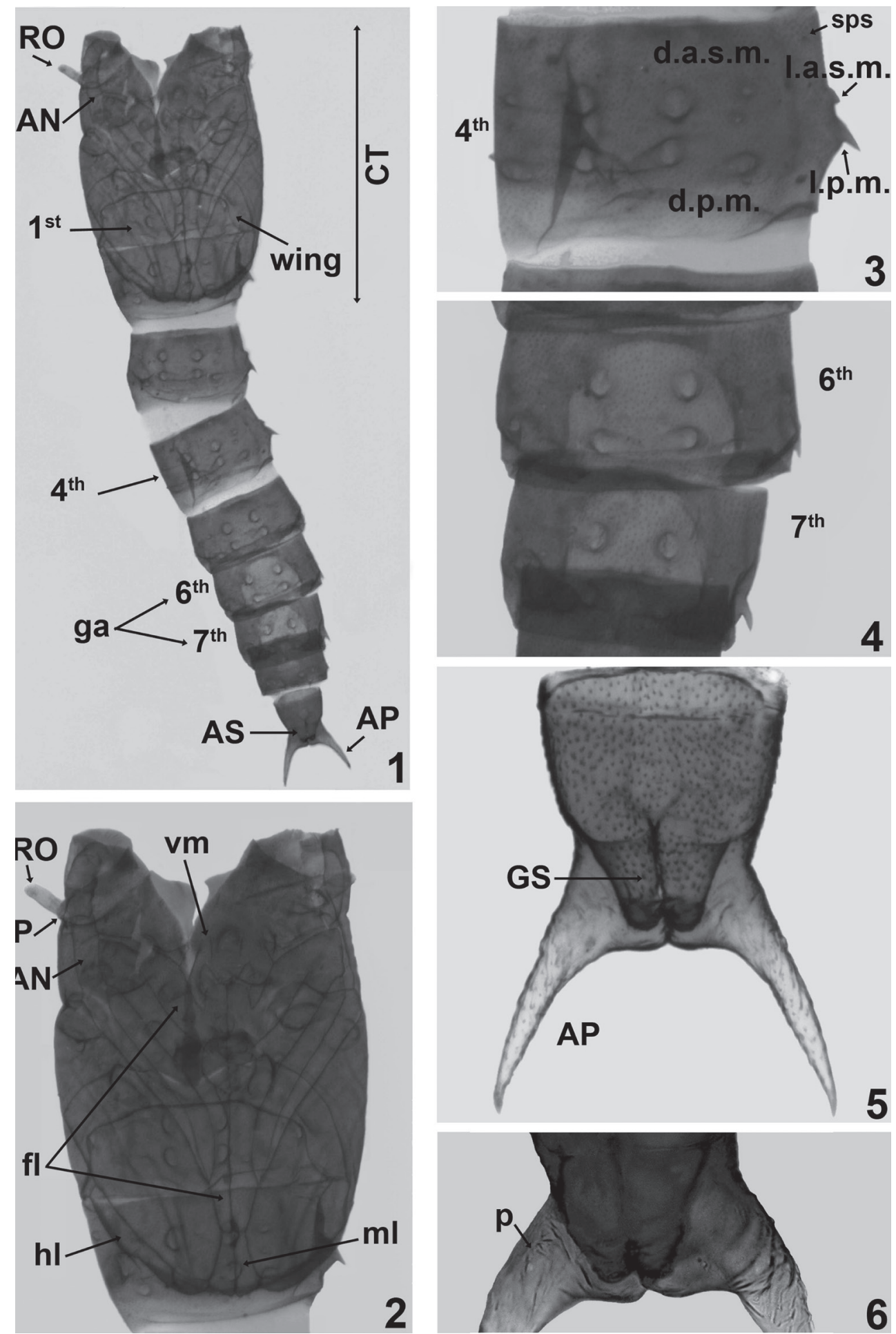

Figures 1-6. Mallochohelea termophila (Spinelli), male pupa. 1, entire pupa (slide mounted specimen), ventral view; 2, cephalothorax, ventral view; $3,4^{\text {th }}$ abdominal segment, dorsal view; $4,6^{\text {th }}$ and $7^{\text {th }}$ abdominal segments, ventral view; 5, anal segment, ventral view; 6 , anal segment detail with pore, ventral view. Antenna (AN); anal segment (AS); apicolateral processes (AP); dorsal anterosubmarginal setae (d.a.s.m.); dorsal posteromarginal setae (d.p.m.); foreleg (fl); glandular areas (ga); genital sac (GS); hindleg (hl); midleg $(\mathrm{ml})$; pedicel (P); lateral anterosubmarginal sete (l.a.s.m.); lateral posteromarginal setae (1.p.m.); pore (p); respiratory organ (RO); ventromedian setae $(\mathrm{vm})$. 

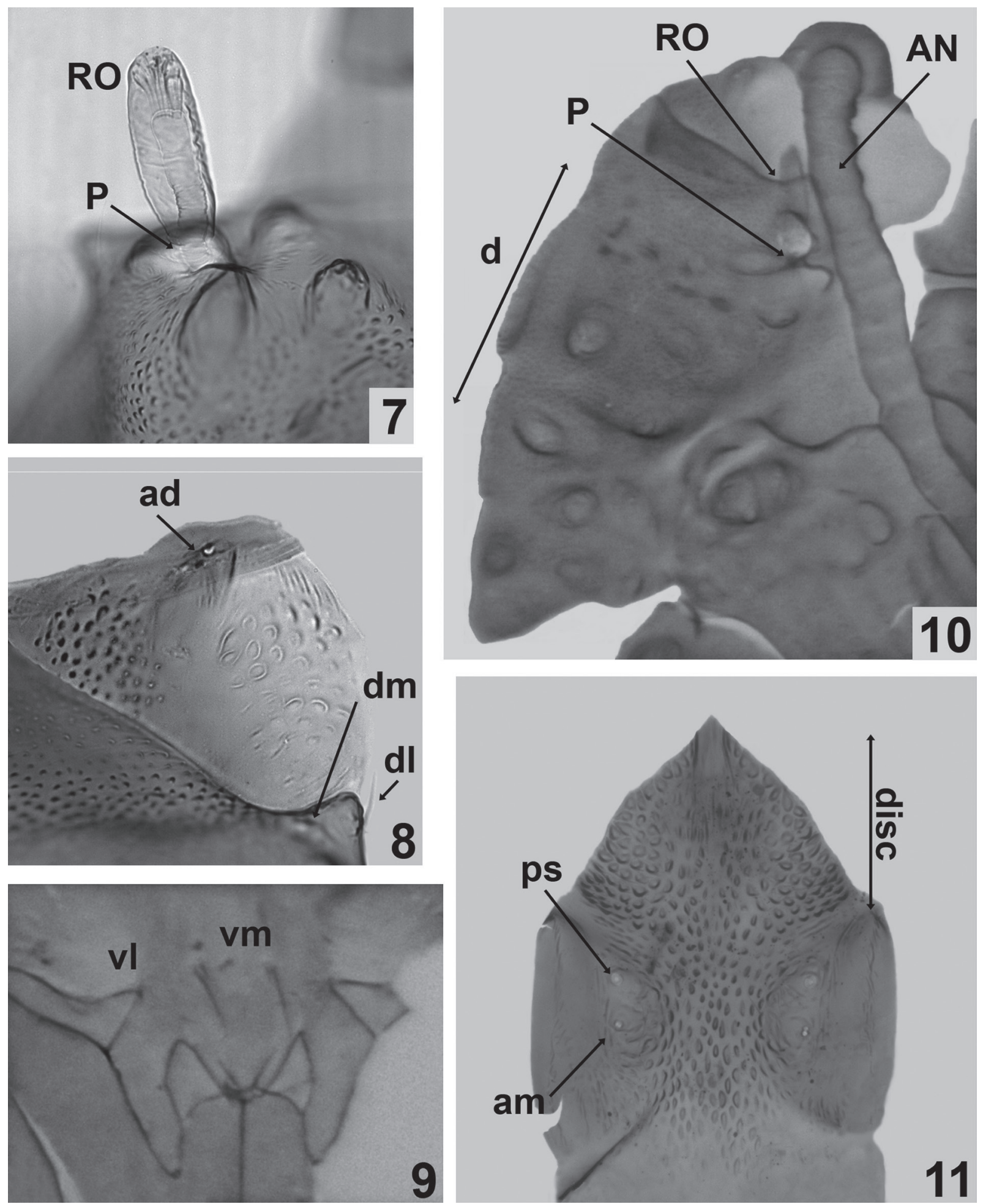

Figures 7-11. Mallochohelea termophila (Spinelli), male pupa. 7, left respiratory organ; 8, anterodorsal setae (ad), dorsolateral seta (dl), dorsomedial setae (dm); 9, mouthparts, ventral view; 10, anterolateral portion of right side of cephalothorax, dorsolateral view; 11, operculum. Anteromarginal setae (am); antenna (AN); dorsal setae (d); pedicel (P); pore at tubercle base (ps); respiratory organ (RO); ventrolateral setae (vl); ventromedian setae (vm). 

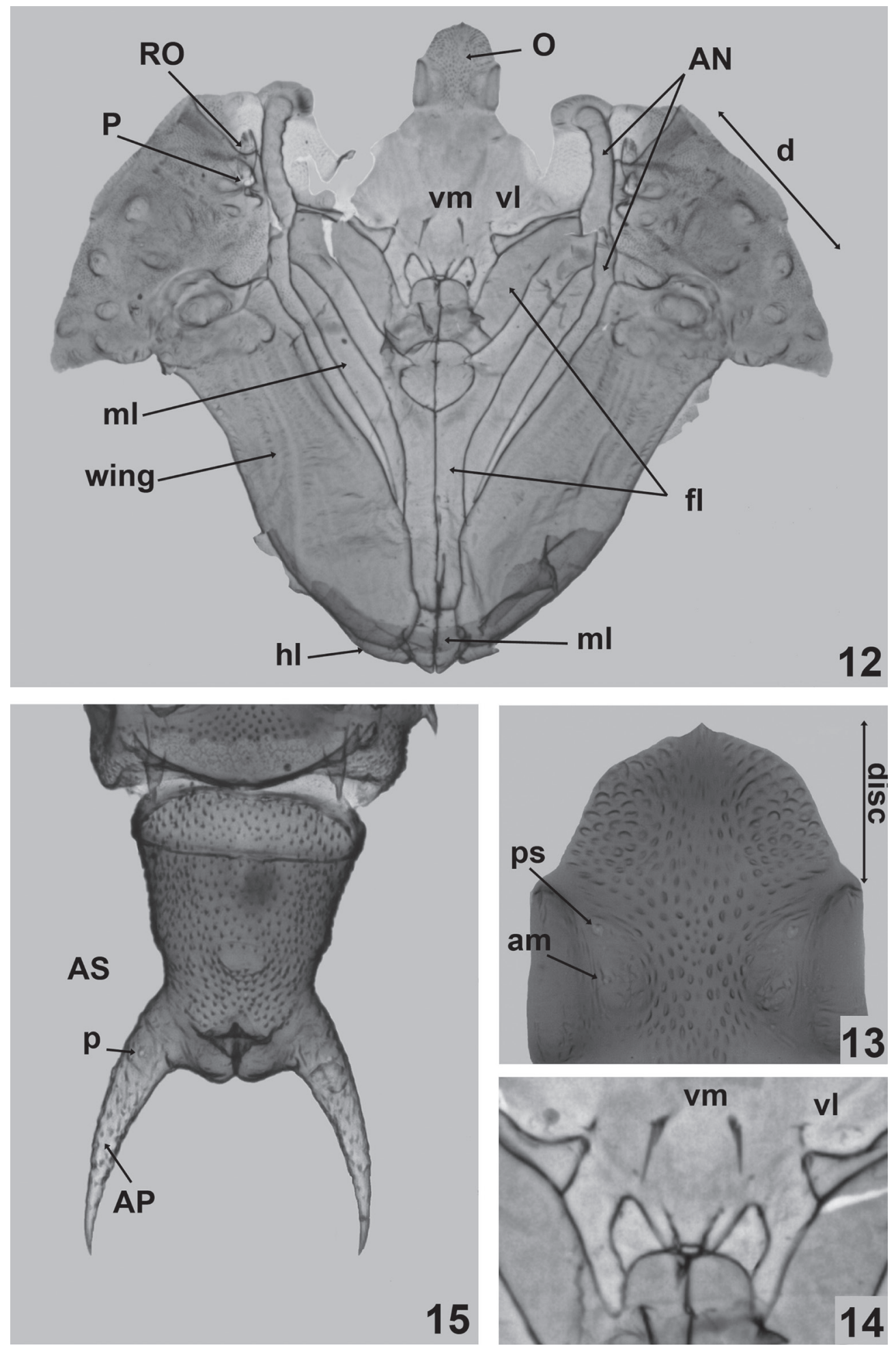

Figures 12-15. Mallochohelea termophila (Spinelli), female pupa. 12, cephalothorax, ventral view; 13, operculum; 14, mouthparts, ventral view; 15, anal segment, ventral view. Anteromarginal setae (am); antenna (AN); anal segment (AS); apicolateral processes (AP); dorsal sensillae (d); foreleg (fl); hindleg (hl); midleg (ml); operculum (O); pedicel (P); pore (p); pore at tubercle base (ps); respiratory organ $(\mathrm{RO})$; ventrolateral setae (vl); ventromedian setae (vm). 


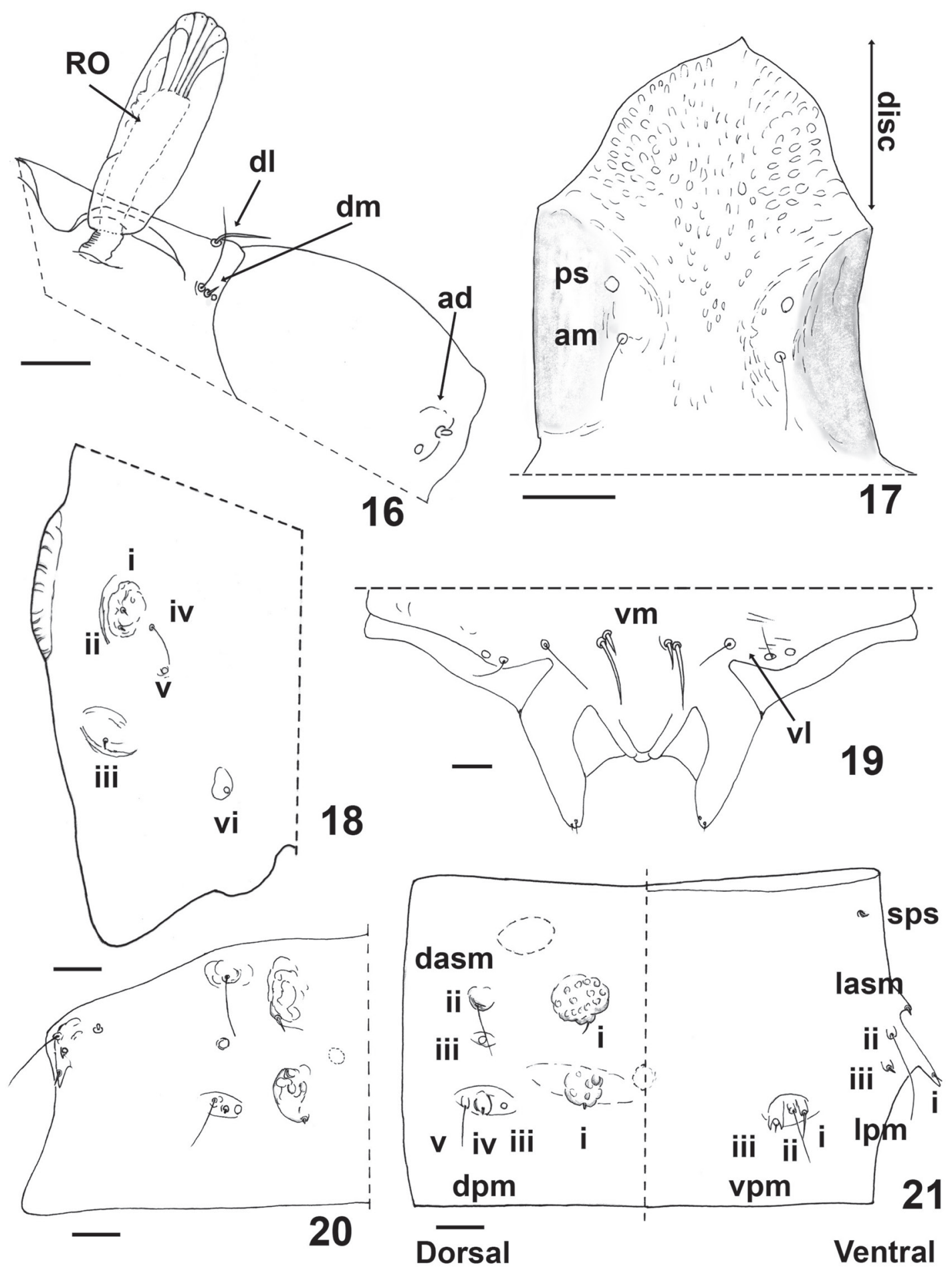

Figures 16-21. Mallochohelea termophila (Spinelli), male pupa. 16, left respiratory organ; 17, operculum; 18, dorsal setae on right side of thorax (d); 19, mouthparts; 20, 1st abdominal segment; 21, 4th abdominal segment. Scale bars $0.05 \mathrm{~mm}$. Anterodorsal setae (ad); anteromarginal setae (am); dorsal anterosubmarginal setae (d.a.s.m.); dorsal posteromarginal setae (d.p.m.); dorsolateral seta (dl); dorsomedial setae (dm); lateral anterosubmarginal seta (1.a.s.m.); lateral posteromarginal setae (1.p.m.); pore at tubercle base (ps); respiratory organ (RO); spiracular scar (sp.s); ventral posteromarginal setae (v.p.m.); ventrolateral setae (vl); ventromedian setae (vm). 
on the respiratory organ, the $\mathrm{vm}$ and $\mathrm{vl}$ are distinctly stronger and longer, and the lasm, vpm and dpm $\mathrm{v}$ are represented by longer setae.

The only other known Neotropical pupa of the tribe Sphaeromiini is the one of Nilobezzia schwarzii (Coquillett), but the latter species exhibits prominent, conical and pointed abdominal tubercles, and the large disc like glandular areas are present on the abdominal sternites 5, 6, and 7 (Wirth, 1962). Moreover, ElsonHarris (1990) pointed out that the Australian pupae of Nilobezzia Wirth show a shorter caudal segment and the bases of 1.p.m. i and ii are clearly separated.

\section{Acknowledgments}

We acknowledge Art Borkent for his kindness in sharing with us part of an unpublished study of Ceratopogonidae pupae, as well as for the detailed review of the manuscript. Our gratitude also goes to Nélida Caligaris for technical assistance in the laboratory.

\section{Literature cited}

Borkent, A. 2012. World Species of Biting Midges (Diptera: Ceratopogonidae). Last updated: February 28, 2011. Available from: http://www.inhs.illinois.edu/research/ FLYTREE/CeratopogonidaeCatalog.pdf; 13.VIII.2012.

Borkent, A. and D. A. Craig. 2001. Submerged Stilobezzia rabelloi Lane (Diptera: Ceratopogonidae) pupae obtain oxygen from the aquatic fern Salvinia minima Baker. Proceedings of the
Entomological Society of Washington 103:655-665.

Borkent, A. and G. R. Spinelli. 2000. Catalog of the New World biting midges south of the United States of America (Diptera: Ceratopogonidae). Contributions on Entomology, International 4:1-107.

Borkent, A. and G. R. Spinelli. 2007. Neotropical Ceratopogonidae (Diptera: Insecta). In Aquatic Biodiversity in Latin America (ABLA), J. Adis, J. R. Arias, G. Rueda-Delgado y K. M. Wnatzen (eds.). Vol. 4. Pensoft, Sofia-Moscow. p. 198.

Borkent, A. and Wirth, W. W. 1997. World species of biting midges (Diptera: Ceratopogonidae). Bulletin of the American Museum of Natural History 233:1-257.

Elson-Harris, M. M. 1990. Keys to the immature stages of some Australian Ceratopogonidae (Diptera). Journal of the Australian Entomological Society 29:267-275.

Spinelli, G. R. 1984. Notas sobre Ceratopogonidae (Diptera: Nematocera) de la República Argentina. IV. Descripción de adulto y pupa de Neobezzia termophila. sp. nov. Neotrópica 30:197-200.

Spinelli, G. R. and W. W. Wirth. 1993. Los Ceratopogonidos de la Argentina (Insecta: Diptera). In Fauna de Agua dulce de la República Argentina, Z. A. de Castellanos (ed.). Vol 38. Diptera, Fascículo 3. Ceratopogonidae. 124 p.

Wirth, W. W. 1962. A reclassification of the Palpomyia-BezziaMacropeza group, and a revision of the North American Sphaeromiini (Diptera, Ceratopogonidae). Annals of the Entomological Society of America 55:272-287.

Wirth, W. W. and N. Marston. 1968. A method for mounting small insects on microscope slides in Canada balsam. Annals of the Entomological Society of America 61:783-784. 